\title{
Child's Cardiopathies at the Hospital De La Paix in Ziguinchor (Senegal)
}

\section{Simon Joël Manga ${ }^{*}$, Sena Laurenda Houngbeme², Mohamed Leye ${ }^{3}$, Lamine Thiam², Sidy Lamine Sy", Quinta Indafa Te ${ }^{1}$}

${ }^{1}$ Cardiology Department, Hospital De La Paix, Assane Seck University of Ziguinchor, Ziguinchor, Sénégal

${ }^{2}$ Paediatric Department, Hospital De La Paix, Assane Seck University of Ziguinchor, Ziguinchor, Sénégal

${ }^{3}$ Cardiology Department, Regional Hospital of Mbour, Thiès University, Thies, Sénégal

${ }^{4}$ Cardiologie Department, Fann National University Center, Dakar, Sénégal

Email: *mangasimon@yahoo.fr

How to cite this paper: Manga, S.J., Houngbeme, S.L., Leye, M., Thiam, L., Sy, S.L. and Te, Q.I. (2022) Child's Cardiopathies at the Hospital De La Paix in Ziguinchor (Senegal). Open Journal of Epidemiology, 12, 50-56.

https://doi.org/10.4236/ojepi.2022.121004

Received: November 26, 2021

Accepted: February 5, 2022

Published: February 8, 2022

Copyright (c) 2022 by author(s) and Scientific Research Publishing Inc. This work is licensed under the Creative Commons Attribution International License (CC BY 4.0).

http://creativecommons.org/licenses/by/4.0/

\begin{abstract}
Introduction: Childhood heart disease consists of congenital and acquired heart disease. The aim of this study was to describe the epidemiological profile and the clinical and aetiological characteristics of childhood heart disease at the Hôpital de la Paix in Ziguinchor. Method: This was a retrospective study from 1 January 2016 to 1 June 2020 in the cardiology and paediatrics departments of the Hôpital de la Paix in Ziguinchor. We included in the study all patients aged 0 - 18 years, hospitalised with heart disease confirmed by cardiac ultrasound. Results: In total, we included 57 patients in the study. The hospital prevalence was $1.6 \%$. The average age was $67.85 \pm 65$ months. The predominance was male with a sex ratio of 0.96 . The majority of mothers (50\%) were between 15 and 30 years old. In our study, 8.85\% of patients had a history of previous angina. Trisomy 21 was present in $12.35 \%$ of our patients. Severe acute malnutrition was found in $21.05 \%$ of cases. Lower limb oedema (82.4\%) and dyspnoea (59.6\%) were the most frequent clinical signs. On cardiac ultrasound, $52.6 \%$ of patients had congenital heart disease and $47.4 \%$ of patients had acquired heart disease. Ventricular septal defect (33.33\%) was the most common congenital heart disease. Among the acquired heart diseases, mitral insufficiency predominated with $70.8 \%$ of cases. Infective endocarditis was the main complication observed. Management was mainly drug-based with diuretics and ACE inhibitors. No patient had undergone surgery. The in-hospital evolution was favourable in $85.9 \%$ of cases and the mortality rate was $10.5 \%$. Conclusion: Our study showed that congenital heart disease was more frequent than acquired heart disease and that management, particularly surgery, was lacking.
\end{abstract}




\section{Keywords}

Heart Disease, Child, Ziguinchor De La Paix Hospital

\section{Introduction}

Child's cardiopathies are defined as heart disease that may or may not be acquired. There are two groups: congenital cardiopathies which are anomalies of the heart occurring in the course of the formation of the heart during intrauterine life and acquired cardiopathies which refer to the conditions of one or more secondary cardiac tunics to an identifiable infectious or non-infectious cause during ectopic life [1] [2].

Child's cardiopathies are a public health problem in Africa. Their treatment often proves to be difficult because of the low socioeconomic level of the populations and the insufficiency of the technical platform. The performance of diagnostic tools, such as cardiac ultrasound, has influenced the epidemiology of childhood heart disease.

Pediatric cardiology is a growing subspecialty in developing countries. There are very few pediatric cardiology centers in Africa south of the Sahara.

In Africa, statistical data are scarce and the prevalence of child's cardiopathies is poorly understood as it is the subject of few studies.

In Senegal, a screening carried out in schools in Dakar, shows that congenital cardiopathies represented $64.28 \%$ and acquired cardiopathies $35.71 \%$ [3].

Like the West, Senegal does not have a child's heart disease surveillance system to identify the different epidemiological aspects of child's heart disease. Most of the studies are hospital-based and generally relate to isolated congenital heart disease. Most of the studies were carried out in Dakar and none in $\mathrm{Zi}$ guinchor, a city in southern Senegal.

The objective of this work was to describe the epidemiological and diagnostic aspects of cardiopathy in children at the Ziguinchor de la Paix Hospital in order to optimize their management.

\section{Methodology}

We carried out a retrospective study in the pediatric department of the Hospital de la Paix of Ziguinchor from January 1rst, 2016 to June 1rst, 2020.

We included in the study all children aged 0 to 18 years hospitalized in pediatrics for cardiopathy confirmed by ultrasound during the study period.

A cardiac ultrasound was performed in these children presenting these signs suggestive of heart disease on a device of the MEDISON brand. The diagnosis of heart disease was not made until confirmed by echocardiography.

We had not included in the study patients over 18 years of age at the time of the study, suspected heart disease cases not documented by echocardiography and unusable records. 
The data collection base consisted of the files of patients hospitalized for childhood heart disease. The studied parameters concerned socio-demographic data (age, gender, socio-economic level, and consultation time), personal and family past history, hemodynamic constants, functional signs as well as clinical examination data. The results of additional examinations, management and hospital progress were also studied.

These data were entered and analyzed using EPI-INFO version 7 software. The significance level was retained for a value of $\mathrm{p}<0.05$.

We made sure that the confidentiality of study participants was ensured by using personal identification numbers on data collection forms instead of names. Personal identifiers will not be included in study reports. All study files will be kept confidential.

\section{Results}

During the study period, 57 cases of child's cardiopathy were diagnosed out of a total of 3471 admissions, for a hospital prevalence of $1.6 \%$.

A predominance of the female sex was noted, with 29 girls (50.8\%) and 28 boys (49.2\%) for a sex ratio of 0.96 .

Table 1 shows the distribution of patients by age group: the age group between 0 and 12 months (33\%) and between 13 and 60 months (21\%) were the most frequent.

The average age of the mothers was $28 \pm 7.53$ with extremes of 12 and 43 years.

A risk factor was found in 13 women $(22.8 \%)$. It is about consanguinity (17.5\%), a maternal pathology during pregnancy (3.5\%) and smoking found in 1 patient (1.7\%).

The majority of our patients (93\%) had delivered vaginally and obstructed labor was found in $29 \%$ of cases.

A risk factor was found in 15 patients (26.3\%) and none in most of cases, i.e. 73.7\%.

Table 2 presents the risk factors found in our patients: trisomy $21(46.6 \%)$ and recurrent tonsillitis (33.3\%) were the most frequent risk factors in our patients.

Table 1. Distribution by patient age.

\begin{tabular}{ccc}
\hline Age range & Workforce & Percentage (\%) \\
\hline $0-12$ months & 19 & 33.3 \\
$13-60$ months & 12 & 21 \\
$61-120$ months & 13 & 22.9 \\
$121-180$ months & 11 & 19.2 \\
$>180$ months & 2 & 3.6 \\
Total & 57 & 100 \\
\hline
\end{tabular}


Table 2. Distribution of patients according to risk factors.

\begin{tabular}{ccc}
\hline Risk factor & Workforce & Percentage (\%) \\
\hline Aucun & 42 & 73.7 \\
Down syndrome & 7 & 12.35 \\
Angina & 5 & 8.85 \\
Acute malnutrition & 1 & 1.7 \\
Polymalformative syndrome & 1 & 1.7 \\
Low birth weight & 1 & 1.7 \\
Total & 57 & 100 \\
\hline
\end{tabular}

The main functional signs were dyspnea (59.6\%), cough (47.3\%) and chest pain (19.2\%). The main signs found on physical examination were edema of the lower limbs (82.4\%), a heart murmur (57.8\%) and intercostal drawing (28\%). Global heart failure was found in $52.6 \%$ of cases.

Only 16 patients had received an electrocardiogram (ECG) because the department did not have pediatric electrodes. Ventricular hypertrophy (31.2\%), sinus tachycardia (18.7\%) and atrial hypertrophy (18.7\%) were the main abnormalities found. One patient presented with atrial fibrillation.

On cardiac ultrasound, $52.6 \%(\mathrm{n}=30)$ of patients had congenital heart disease and $47.4 \%(\mathrm{n}=27)$ had acquired heart disease.

The most frequent congenital heart diseases were: interventricular communication (33.3\%), tetralogy of Fallot (16.6\%), ductus arteriosus (10\%) and atrioventricular duct (10\%).

Of acquired cardiopathies, it was largely rheumatic valve cardiopathies (89\%); dilated cardiomyopathies (DCM) accounted for $11 \%$ of cases.

Among rheumatic valve cardiopathies, mitral insufficiency (70.8\%) was the main rheumatic valve disease.

Figure 1 shows the different heart diseases found in our study.

Management was primarily medical and the most prescribed drugs were diuretics (75.4\%) and ACE inhibitors (21\%).

The average hospitalization was 2 days \pm 6.52 with extremes ranging from 2 to 9 days.

The evolution in hospital was favorable in the majority of cases $(85.9 \%)$ and complications such as infectious endocarditis were found in 2 patients.

The mortality rate was $10.5 \%(n=6)$. The majority of deaths were observed in patients with congenital heart disease without significant correlation.

Patients with a surgical indication were referred to Dakar, which has the only child cardiac surgery center in Senegal.

\section{Discussion}

The cardiopathy's prevalence appears to increase over time with a significant increase in congenital cardiopathies and a decrease in acquired cardiopathies. The prevalence was $1.6 \%$ in our study, which is comparable to the results of Challengea Mbolla, in the Congo Brazzaville, which found a prevalence of $1.7 \%$ [4]. 


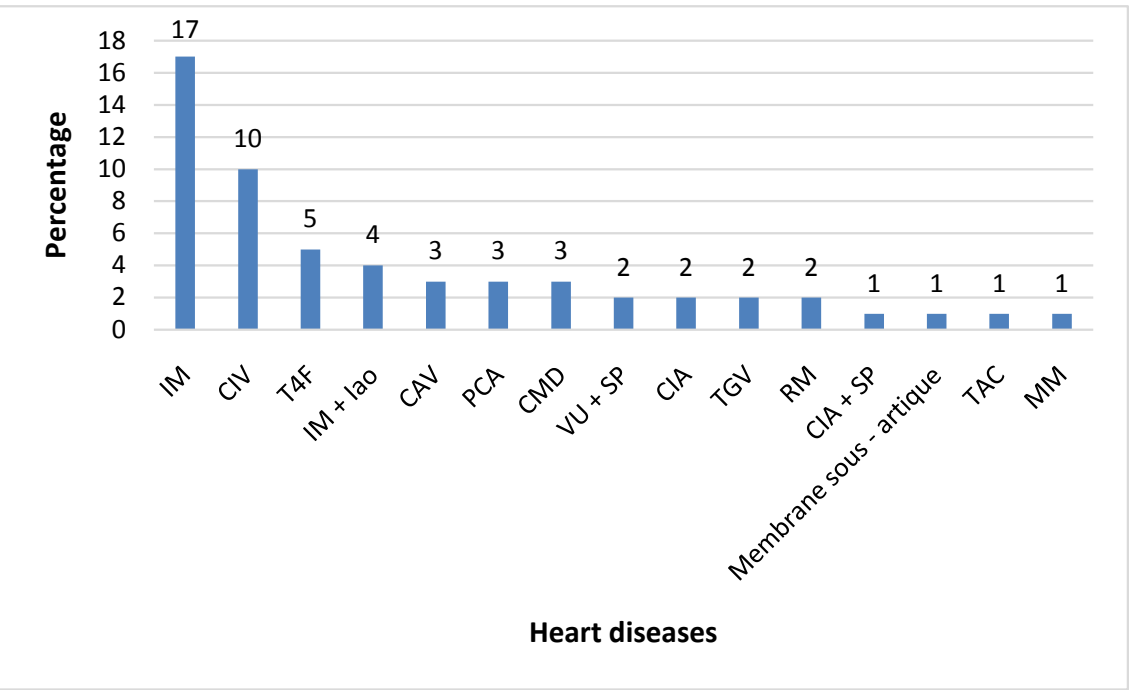

Figure 1. Distribution of patients according to underlying cardiopathies. IM: Mitral Insufficiency CIV: Interventricular communication T4F: Tetralogy of Fallot IM + IAo: Mitral insufficiency + Aortic insufficiency CAV: Atrioventricular canal PCA: Persistence of the ductus arteriosus CMD: Dilated cardiomyopathy VU + SP: Single ventricle + pulmonary stenosis CIA: Interatrial communication TGV: Transposition of the great vessels RM: Mitral stenosis CIA + MS: Interatrial communication + pulmonary stenosis TAC: Common arterial trunk MM: Mitral disease.

Ngouala, in Louga (Senegal), found a lower prevalence of $0.43 \%$ [5]. The upgrading of the technical platform, with the availability of cardiac ultrasound in our facilities, currently allows early detection of congenital cardiopathies.

In our study, a risk factor was found in 13 women (22.8\%). These were consanguinity (17.5\%), a maternal pathology during pregnancy (3.5\%) and smoking found in 1 patient (1.7\%).

Dupuis's work has shown a high frequency of congenital heart disease in communities with a higher rate of consanguinity [6] and According to HOTAYT, consanguinity is a risk factor for congenital cardiopathies, in particular for the single ventricle and interatrial communication [7]. The risk of malformation is around 50\% if infected during the first month of pregnancy and $22 \%$ during the second month. The existence of diabetes, epilepsy or maternal obesity are also associated with an increased risk of heart defects during pregnancy [1].

The detrimental effect of maternal smoking during pregnancy has long been recognized, in particular, the risk of having smaller infants and shorter gestation times, as well as a greater frequency of distress respiratory occurrence in newborns [8]. In the literature, no link has been found between consanguinity, smoking and the occurrence of acquired cardiopathy.

Knowledge of these maternal risk factors should be used in the implementation of primary prevention strategies.

In our study, trisomy $21(12.35 \%)$ and recurrent tonsillitis $(8.85 \%)$ were the most frequent risk factors in our patients. 
Trisomy 21 is a frequent chromosomal abnormality, associated in half of cases with congenital heart disease [1]. The occurrence of recurrent angina due to poorly treated beta-hemolytic streptococcus group $\mathrm{A}$, promotes the occurrence of acute articular rhumatism (AAR) which in turn is complicated by rheumatic cardiopathies [9]. AAR remains a public health problem in developing countries.

In our study, congenital cardiopathies were more common than acquired cardiopathies and this trend is reported by several studies [4] [5]. Improved technical facilities allow early detection and the adequate treatment of infections due to group A beta-hemolytic streptococcus has also reduced the incidence of rheumatic cardiopathies.

The most frequent congenital cardiopathies in our study was VIC, which was found in 33.3\% of cases. Several studies find results similar to ours [5] [10] [11]. IVC is the most frequent congenital cardiopathies in term newborns, accounting for nearly $30 \%$ of congenital cardiopathies [12].

Our study also confirmed that mitral insufficiency was the most frequent rheumatic valve disease found in $70.8 \%$ of cases in our study and these results are corroborated by several authors [4] [5] [10].

The treatment was primarily medical in our study. Limited access to surgery is a limit to the management of child's cardiopathy in our regions.

The mortality rate, of $10.5 \%$ in our study, was lower than that of Ellenga Mbolla who found a mortality rate of $24 \%$. Child's cardiopathy is a public health problem in Africa due to limited access to treatment, especially surgical treatment; which affects the prognosis of our patients.

The limitations of this work are related to the retrospective nature of the study and the limited size of our sample.

The real estimation of their prevalence requires the realization of multicenter and multidisciplinary prospective studies between gynecologists, pediatricians and cardiologists.

\section{Conclusion}

Child's cardiopathy is a real problem of diagnosis and management in Africa. Congenital cardiopathies are more common than acquired cardiopathies and identifying maternal risk factors may help reduce their incidence.

\section{Authors' Contribution}

All the authors contributed to the conduct of this work. All authors have read and approved the latest version of this manuscript.

\section{Conflicts of Interest}

The authors declare no conflicts of interest regarding the publication of this paper.

\section{References}

[1] Cohen, S. and Bajolle, F. (2017) Épidémiologie, étiologie et génétique des cardiopa- 
thies congénitales. EMC-Cardiologie, 12, 1-14.

[2] Vahanian, A., Garbarz, É. and Iung, B. (2011) Les cardiopathies acquises de l'enfant dans les pays en voie de développement. Bulletin de l'Académie nationale de médecine, 195, 315-326. https://doi.org/10.1016/S0001-4079(19)32090-4

[3] Bodian, M., Ngaidé, A.A., Mbaye, A., Sarr, S.A., Jobe, M. and Ndiaye, M.B. (2015) Prévalence des cardiopathies congénitales en milieu scolaire coranique (daara) à Dakar: étude transversale basée sur le dépistage clinique et échographique de 2019 élèves. Bulletin de la Société de pathologie exotique, 108, 32-35. https://doi.org/10.1007/s13149-014-0410-5

[4] Ellenga-Mbolla, B., Oko, A., Okoko, A.R., Moyen, E., Ekouya-Bowassa, G. and Gombet, T.R. (2014) Pronostic immédiat des cardiopathies prises en charge dans le service des soins intensifs pédiatriques du CHU de Brazzaville. Médecine et Santé Tropicales, 24, 204-207. https://doi.org/10.1684/mst.2014.0330

[5] Ngouala, G.A., Affangla, D.A., Leye, M. and Kane, A. (2015) Prevalence des cardiopathies infantiles symptomatiques au Centre Hospitalier Régional de Louga, Senegal. Cardiovascular Journal of Africa, 26, 1-5. https://doi.org/10.5830/CVJA-2015-031

[6] Dupuis, C., Kachaner, J. and Liberté, R. (1991) Cardiologie pédiatrique. $2^{\mathrm{e}}$ édition. Flammarion, Paris, 137-1342.

[7] Hotayt, S., Abi Nader, E., Saliba, Z., Daou, L., Chehab, G. and El Rassi, I. (2055) Cardiopathies congénitales et consanguinité au Liban. Archives de pédiatrie, 22, 285-208. https://doi.org/10.1016/S0929-693X(15)30388-2

[8] Steyn, K., De Wet, T., Saloojee, Y. and Yach, D. (2006) The Influence of Maternal Cigarette Smoking, Snuff Use and Passive Smoking on Pregnancy Outcomes: The Birth to Ten Study. Paediatric and Perinatal Epidemiology, 20, 90-99. https://doi.org/10.1111/j.1365-3016.2006.00707.x

[9] Azagoh-Kouadio, R., Diby, K.F., Yeboua, K.R., Avi, C., Aka-Tanoh, A.H. and Gnaba, L.A. (2019) Cardiopathies acquises de l'enfant en Côte d'Ivoire: Étude rétrospective multicentrique. Revue International des Sciences Médicales, 21, 284-292.

[10] Tougouma, S.J.B., Kissou, S.L.A., Yaméogo, A.A., Yameogo, N.V., Bama, A. and Barro, M. (2016) Les cardiopathies de l'enfant au CHU Souro Sanou de Bobo-Dioulasso: Aspects échocardiographies et thérapeutiques. The Pan African Medical Journal, 25, 62. https://doi.org/10.11604/pamj.2016.25.62.9508

[11] Joly, H., Dauphin, C. and Montreff, P. (2004) Communication interventriculaire du nourrisson : évolution à court terme (série prospective de 89 cas)/Ventricular septal defect of neonate. Archives des Maladies du Cour et des Vaisseaux, 97, 540-545.

[12] Boët, A. (2019) Cardiopathies congénitales. EMC-Traité de Médecine Akos, 14, $1-8$. 